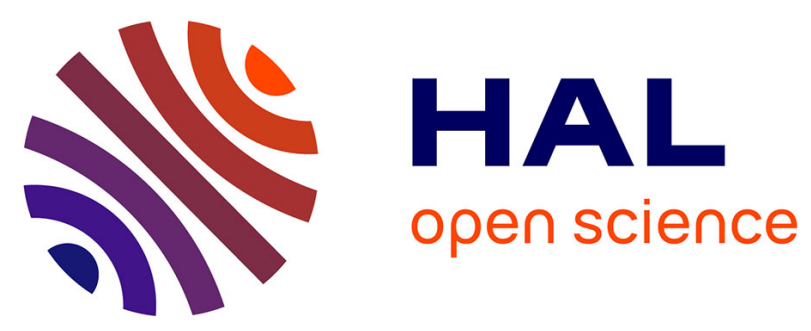

\title{
Numerical continuation of a physical model of brass instruments: Application to trumpet comparisons
}

Vincent Fréour, Louis Guillot, Hideyuki Masuda, Satoshi Usa, Eiji Tominaga, Yutaka Tohgi, Christophe Vergez, Bruno Cochelin

\section{To cite this version:}

Vincent Fréour, Louis Guillot, Hideyuki Masuda, Satoshi Usa, Eiji Tominaga, et al.. Numerical continuation of a physical model of brass instruments: Application to trumpet comparisons. Journal of the Acoustical Society of America, 2020, 148 (2), pp.748-758. 10.1121/10.0001603 . hal-03094997

\section{HAL Id: hal-03094997 https://hal.science/hal-03094997}

Submitted on 5 Jan 2021

HAL is a multi-disciplinary open access archive for the deposit and dissemination of scientific research documents, whether they are published or not. The documents may come from teaching and research institutions in France or abroad, or from public or private research centers.
L'archive ouverte pluridisciplinaire HAL, est destinée au dépôt et à la diffusion de documents scientifiques de niveau recherche, publiés ou non, émanant des établissements d'enseignement et de recherche français ou étrangers, des laboratoires publics ou privés. 


\title{
Numerical continuation of a physical model of brass instruments:
}

\author{
application to trumpet comparisons
}

Vincent Fréour $^{1}$, Louis Guillot ${ }^{2}$, Hideyuki Masuda $^{1}$, Satoshi Usa $^{1}$, Eiji Tominaga ${ }^{1}$, Yutaka Tohgi ${ }^{1}$ Christophe Vergez ${ }^{2}$, Bruno Cochelin²

${ }^{1}$ YAMAHA Corporation, Research and Development Division, 10-1 Nakazawa-cho, Naka-ku, Hamamatsu, Shizuoka 430-8650, Japan.

${ }^{2}$ Aix Marseille Univ., CNRS, Centrale Marseille, LMA UMR7031, Marseille, France

\begin{abstract}
Summary
The system formed by a trumpet player and his/her instrument can be seen as a non-linear dynamical system, and modeled by physical equations. Numerical tools can then be used to study these models and clarify the influence of the model parameters. The acoustic input impedance, for instance, is strongly dependent on the geometry of the air column and is therefore of primary interest for a musical instrument maker. In this study, a method of continuation of periodic solutions based on the combination of the Harmonic Balance Method (HBM) and the Asymptotic Numerical Method (ANM), is applied to a physical model of brass instruments. It allows the study of the evolution of the system where one parameter of the model (static mouth pressure) varies. This method is used to compare different $\mathrm{B} b$ trumpets on the basis of two descriptors (hysteresis behavior and dynamic range) computed from the continuation outputs. Results show that this methodology enables to differentiate instruments in the space of the calculated descriptors. Calculations for different values of the lip parameters are also performed to confirm that the obtained categorization is independent of variations of lip parameters.
\end{abstract}

\section{Introduction}

In wind instruments, where the basic mechanisms of sound production have been well described in the literature $[1]$, the modeling of the dynamical system formed by the \{player - instrument couple has been a research topic of growing interest. In brass instruments, the lip excitation mechanism is commonly modeled by a simple one-degree-of-freedom mechanical oscillator, non-linearly coupled to the air-column of the instrument by a flow model [4 6]. More advanced representations of this model have been considered by concentrating on the fluidstructure interaction between the air-jet and the lips [7], the number of degrees of freedom for the lips [8, 9], the acoustical interaction with the upstream airways [10,11], or the nonlinear propagation inside the bore of the 
instrument 12 14].

The nonlinear dynamical system formed by the couple \{player - instrument\} can then be studied by numerical methods allowing to characterize the behavior of the system. In wind instruments, Linear Stability Analysis (LSA) allows to determine the linear oscillation threshold of the instrument with respect to the quasi-static mouth pressure for instance 15 17]. More recently, continuation methods have been applied to the study of woodwind musical instruments, allowing to calculate bifurcation diagrams that provide a global view of the behavior of the instrument (stability of the different periodic regimes, change of regime, etc.) [18].

Meanwhile, music instrument makers have been interested in the contribution of scientific methods to the development of acoustic wind instruments. This particularly requires a more advanced understanding of the relationships between certain design choices (geometry of the air column, material) and the behavior of the \{player - instrument \} system. These questions are also triggered by the emergence of new materials and manufacturing processes, that provide new possibilities with regards to the design of music instruments, and which acoustical and vibroacoustical effects remain to be clarified.

The question of correlating design attributes to players perceptual experience of an instrument is not new in the musical acoustics literature. Several studies attempt to provide answers to that complex problem with more or less success 19]. Another complementary approach consists of extracting objective descriptors from measurements, with the aim to categorize and highlight differences between instruments on the basis of more advanced or meaningful indicators 20 22], the underlying assumption being that these indicators may then be easier to correlate to perceptual data. Some studies have followed this strategy, particularly in string instruments. More specifically, these studies were able to provide quantitative descriptors allowing comparisons of instruments based on global mechanical parameters of the body 20], specific features extracted from the bridge admittance [21, or the emergence of inharmonic body components in plucked sounds 22]. In one study, the proposed descriptors could be correlated to a perceptual classification proposed by the manufacturer, but these results could hardly be generalized to a larger pool of evaluators 21. In brass instruments, some work was conducted on the trumpet using physical modelling and frequency-domain simulations in order to investigate differences in tuning and timbre between different instruments 23 . The results were compared with controlled perceptual listening tests, showing the ability of the simulated sound to replicate some differences produced in real playing conditions, especially in terms of tuning.

Finally, addressing this problematic is particularly motivated by the important similarities that can be observed between instruments when looking at their acoustic characteristics. Figure 1 represents the input impedance of two high-end $\mathrm{B} b$ trumpets developed and commercialized by two different makers. The differences between these curves are relatively small despite perceived differences reported by the players, and reflect small differences in the geometry of the air columns. These small differences are also visible in the modal parameters extracted by the modal analysis described in Section B (cf. Fig. 2).This observation hence confirms the need for methods and strategies suitable to highlight differences between instruments, as well as capable of providing 
quantitative indicators that can be more easily connected to the performance of the instrument. We remind that the effects of the bore material and bore vibrations include a potential vibro-acoustic coupling with the air-column that, if it occurs, is included in the impedance [24]. Other effects, such as radiation of the wall or mechanical coupling with the player are not considered here.
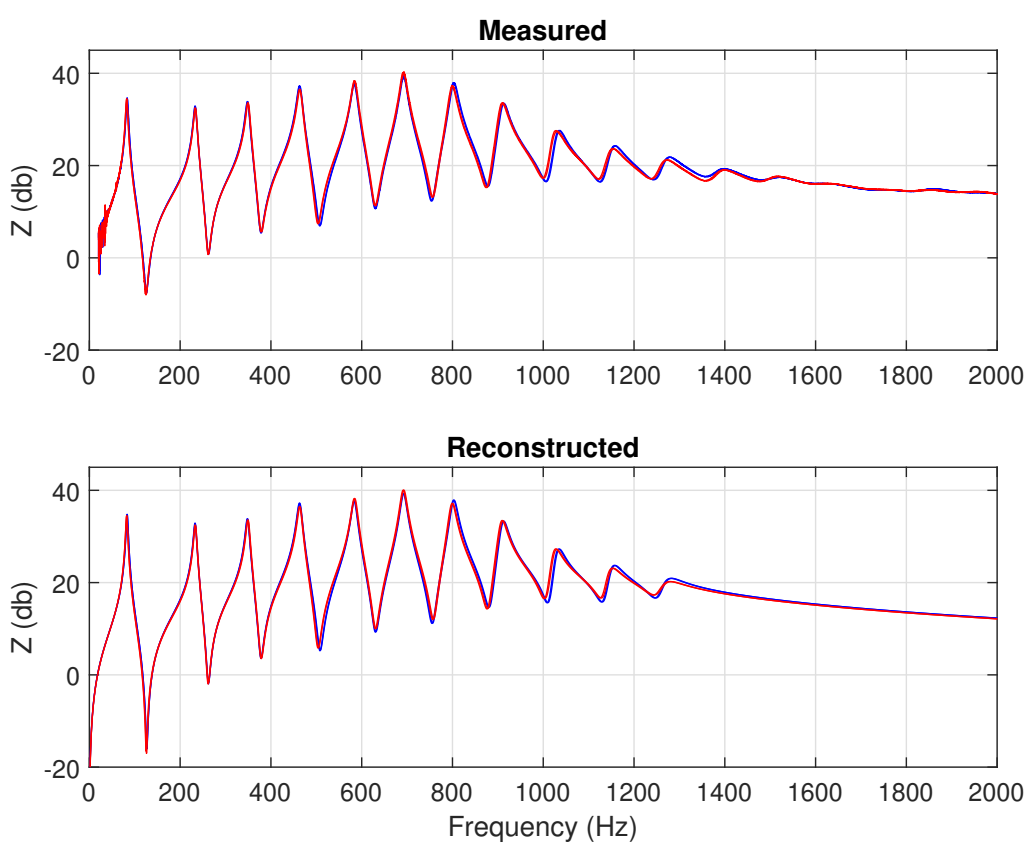

Figure 1: (Color online) Input impedance normalized by the characteristic impedance of two $\mathrm{B} b$ trumpets (two curves per trumpet) from two different makers. Measurement (top), reconstruction after modal analysis (bottom).
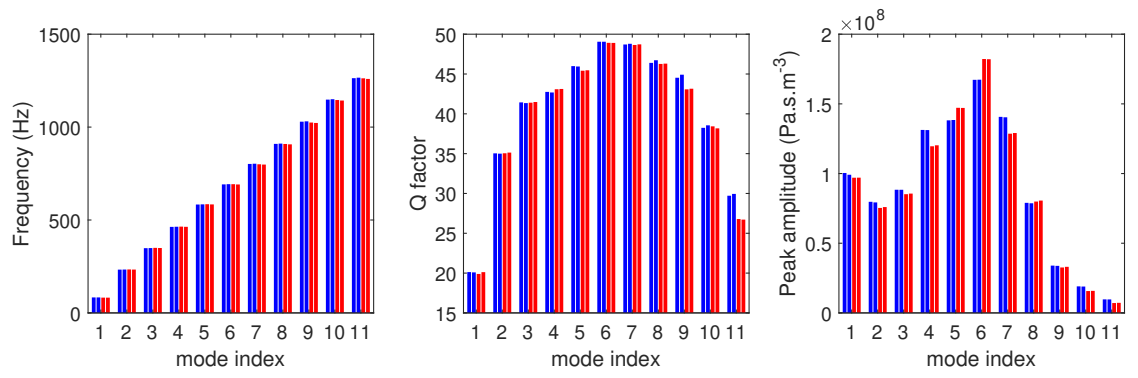

Figure 2: Modal parameters extracted from the measured impedances of two $\mathrm{B} b$ trumpets (two measurements per trumpet).

Therefore, the aim of this study is to apply a numerical continuation method to a physical model of brass instrument, with the objective of extracting quantitative descriptors allowing to categorize a number of high-end $\mathrm{B} b$ trumpets, on the basis of descriptors connected to playing attributes. This paper is organized as follows: the physical model of the system is presented in Section 2, the fundamentals of the continuation method used in this study is provided in Section 3. Results and discussions are presented in Sections 4 and 5. 


\section{${ }_{69}$ II Physical model of a trumpet}

\section{A Equations of the model}

The model chosen in order to describe the non-linear dynamical system \{player - instrument is based on three ingredients: 1) a mechanical equation describing the dynamics of the lips excitation; 2) an acoustic equation describing the linear acoustical behavior of the air column; 3) a flow equation coupling the two previous elements.

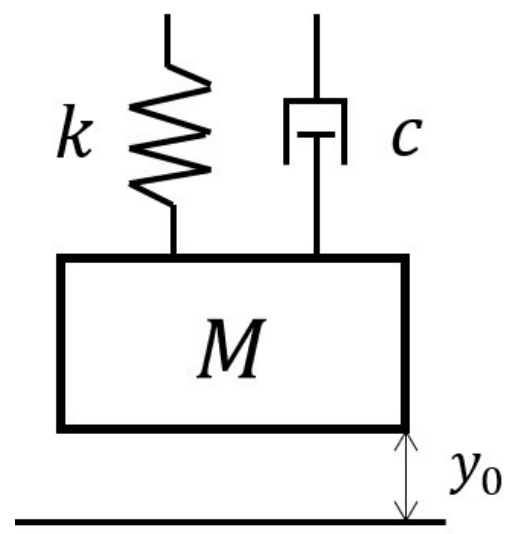

Figure 3: One-dof lip model with mass $M$, stiffness $k$, damping $c$ and lip position at rest $y_{0}: k=M \omega_{l}^{2}$, $c=M \omega_{l} / Q_{l}$.

The model chosen for the lips is a one-dof outward striking model (Fig. 3 ) described by the following secondorder differential equation, used in previous studies $5,6,17$ :

$$
\ddot{y}+\frac{\omega_{l}}{Q_{l}} \dot{y}+\omega_{l}^{2}\left(y-y_{0}\right)=\frac{1}{\mu_{l}}\left(p_{0}-p(t)\right)
$$

where $y$ is the vertical position of the lips, $y_{0}$ is the lip position at rest, $\omega_{l}$ is lip resonance frequency (in radians/s), $Q_{l}$ is the lip $\mathrm{Q}$ factor, $\mu_{l}$ is the lip mass per unit surface area, and $p$ and $p_{0}$ are the downstream (mouthpiece) and upstream (mouth) pressure, respectively. The pressure difference across the lips generates a volume flow $u(t)$ at the input of the instrument. Considering a quasi-stationary flow with dissipation of the kinetic energy of the jet and no pressure recovery in the mouthpiece, and under the hypothesis of an uncompressible fluid, the volume flow $u(t)$ can be simply calculated using the Bernoulli theorem:

$$
u(t)=\sqrt{\frac{2\left|p_{0}-p\right|}{\rho}} \cdot b \cdot \operatorname{sign}\left(p_{0}-p(t)\right) \cdot \theta(y(t)),
$$

where $b$ is the lip opening width assumed to be constant, $\operatorname{sign}\left(p_{0}-p(t)\right)=-1$ if $\left(p_{0}-p(t)\right)$ is negative and +1 otherwise, and where $\theta=\frac{|y|+y}{2}$ is the Heaviside function which is used to force the flow $u(t)$ to zero if $y(t)$ is negative. This condition on $u(t)$ when $y(t)<0$ is motivated by the intention to keep the model simple (with a limited number of parameters), without having to include a model of contact when the lips completely close. The acoustical behavior of the instrument is described by its frequency-domain input impedance $Z(\omega)=\frac{P(\omega)}{U(\omega)}$ 
which linearly relates the volume flow $U(\omega)$ and pressure $P(\omega)$ at the input of the instrument. The input impedance is here represented by considering a mathematical pole-residue model of $N$ poles $s_{k}$ and residues $C_{k}$, corresponding to the $N$ different acoustic modes (we refer here to the different resonances induced by the plane-wave mode) of the air column [25]:

$$
Z(\omega)=Z_{c} \sum_{k=1}^{N} \frac{C_{k}}{j \omega-s_{k}}+\frac{C_{k}^{*}}{j \omega-s_{k}^{*}},
$$

where $C_{k}^{*}$ and $s_{k}^{*}$ stand for the complex conjugates of $C_{k}$ ad $s_{k}$ respectively. Each complex pressure component $P_{k}(\omega)$ is then calculated such as:

$$
P_{k}(\omega)=Z_{c} \frac{C_{k}}{j \omega-s_{k}} U(\omega),
$$

which in the time domain writes as follows:

$$
\dot{p}_{k}(t)=Z_{c} C_{k} u(t)+s_{k} p_{k}(t) .
$$

It can be shown that, because of the hermitian symmetry property of the volume flow, the acoustic pressure in the mouthpiece $p(t)$ is given by the following relation 25]:

$$
p(t)=2 \sum_{k=1}^{N} \Re\left(p_{k}(t)\right) .
$$

\section{B Modal parameters of the impedance}

In order to estimate the modal coefficients $C_{k}$ and $s_{k}$ used in Eq. 5, modal analysis (using a high-resolution subspace method [28]) is applied to the input impedance of the trumpets, measured using an impedance sensor. The $N$ poles $s_{k}$ and residues $C_{k}$ extracted by the high-resolution analysis then become inputs of the physical model. The input impedance is measured in open fingering (no valve pressed) using a sensor developed and commercialized by the Center of Technology Transfer of le Mans (CTTM) and based on a back-cavity method [26]. The same mouthpiece is used for all trumpets measured in this study. The input impedance is measured from $20 \mathrm{~Hz}$ to $2 \mathrm{kHz}$ and the frequency axis corrected to $27^{\circ} \mathrm{C}$, an estimate of the temperature inside the instrument 27]. The complex frequency-domain impedance obtained is then converted into a time-domain impulse response $h(t)$ as follows:

1. Low-frequency logarithmic interpolation of the real part of the input impedance $\Re(Z)$, and linear interpolation of the imaginary part of the input impedance $\Im(Z)$ down to $0 \mathrm{~Hz}$.

2. High-frequency interpolation of $\Re(Z)$ and of $\Im(Z)$ between $2 \mathrm{kHz}$ and $4 \mathrm{kHz}$, so that $\Re(Z)$ is constant and $\Im(Z)$ decreases linearly. 
3. $Z$ is made hermitian: $Z(-\omega)=\bar{Z}(\omega)$.

4. Inverse Fourier transform is applied.

The low-frequency interpolation process is illustrated in Fig 4 . For the real part of $Z$, a section of the measured impedance is selected and smoothed by a moving average filter between $40 \mathrm{~Hz}$ and $60 \mathrm{~Hz}$ (red line in Fig 4 ). This section is then used to perform a logarithmic interpolation down to $0 \mathrm{~Hz}$, which guarantees $\Re(Z)>0$ at $0 \mathrm{~Hz}$, as it is expected (flow resistance). For the imaginary part, a simple linear extrapolation is performed from $20 \mathrm{~Hz}$ to $0 \mathrm{~Hz}$ with the constraint $\Im(Z)=0$ at $0 \mathrm{~Hz}$.
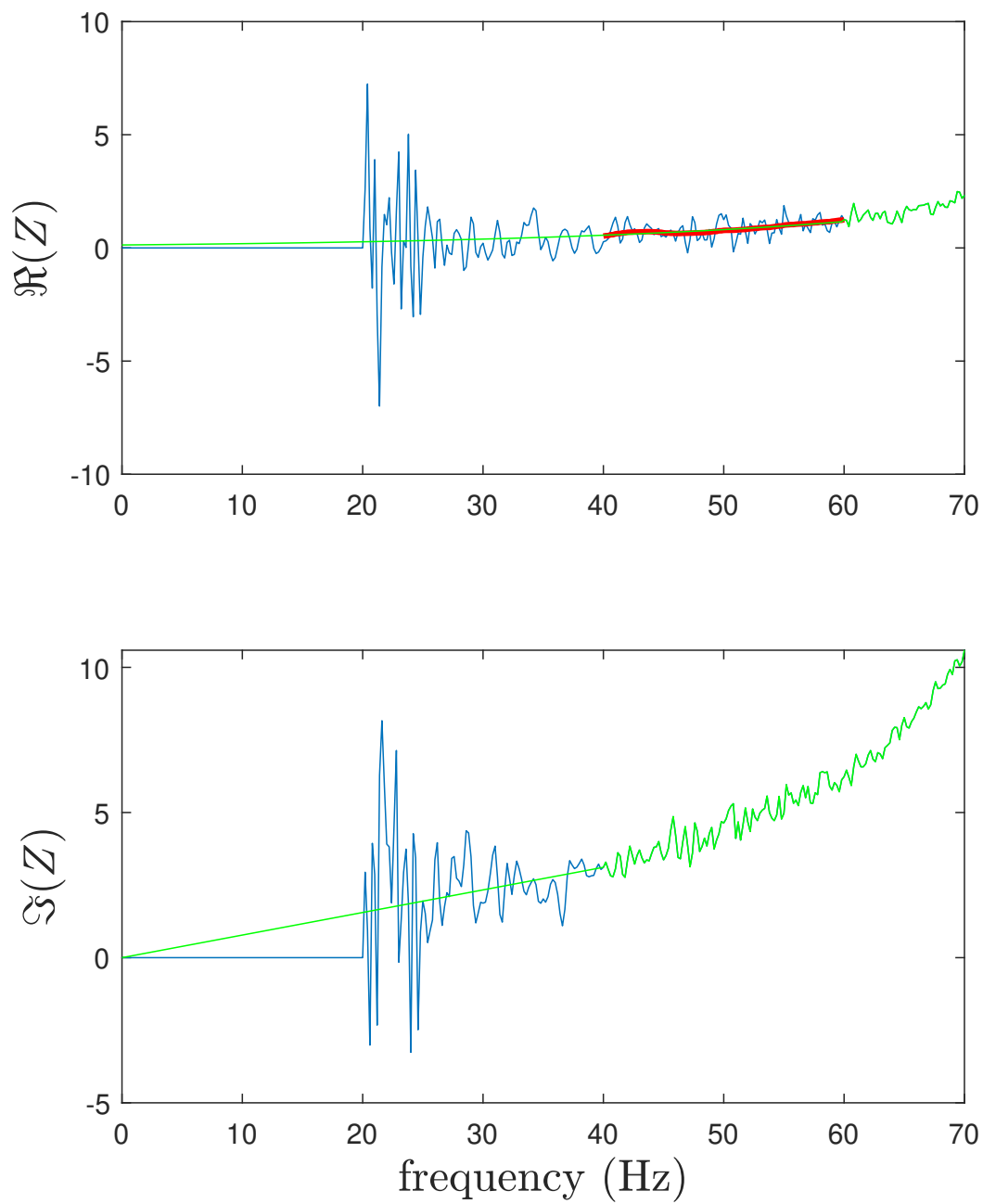

Figure 4: (Color online) Low-frequency interpolation of the real part (top) and imaginary part (bottom) of $Z$, blue: measured $Z$, green: interpolated $Z$, red: smoothed section of $Z$ used for the extrapolation of $\Re(Z)$.

The modal parameters $C_{k}$ and $s_{k}$ are then extracted from the impulse response $h(t)$ using the high resolution subspace method ESPRIT 28. The modal parameters are related to the impulse response as follows: 


$$
h(t)=2 \Re\left\{Z_{c} \sum_{k=1}^{N} C_{k} \mathrm{e}^{s_{k} t}\right\}
$$

The order of the analysis (number of poles considered for the analysis) is estimated using the ESTER criterion [29. For the trumpets analyzed in open fingering (no valve pressed), the number of modes considered varies between 11 and 12 modes depending on the instrument. For more details about the application of ESPRITESTER to modal analysis, the reader is invited to refer to 20,22, 30 .

An example of measured and reconstructed impedance using Eq. 3 on the basis of 11 complex modes is presented in Fig. 5. The amplitude difference between the measured and reconstructed impedances remains below $2.5 \%$ across the frequency range of interest $[0-2 \mathrm{kHz}]$.

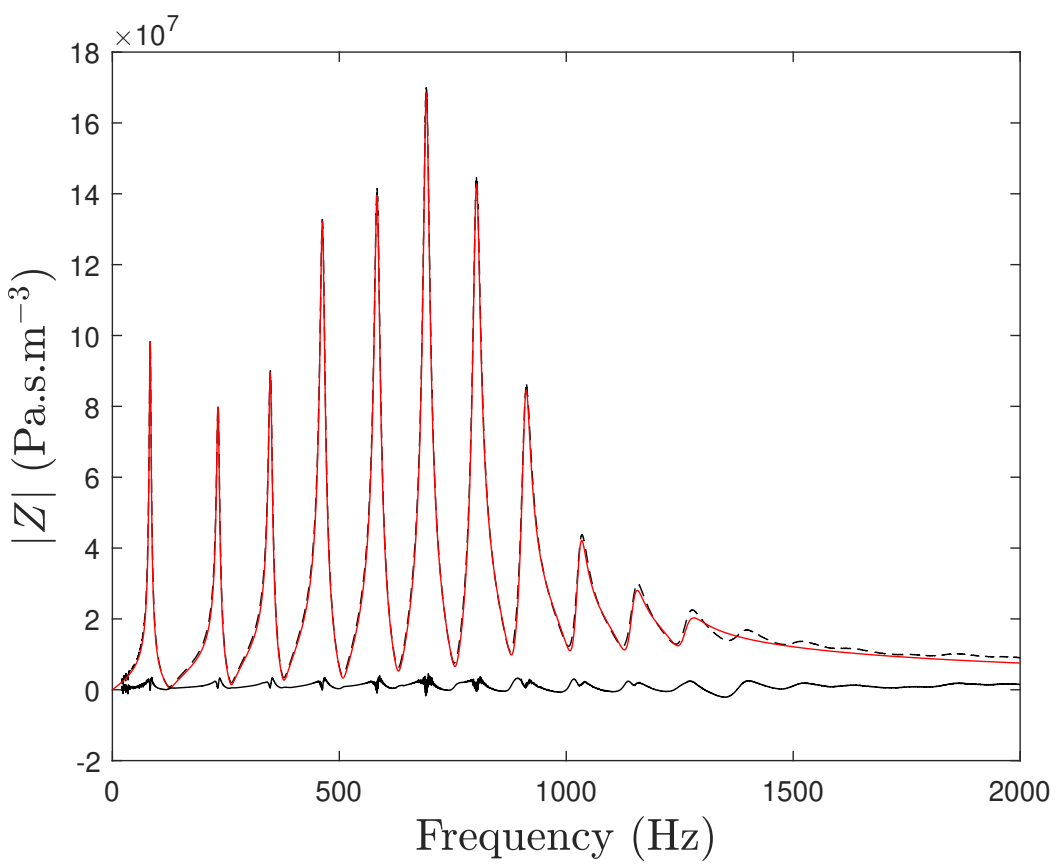

Figure 5: (Color online) Reconstructed input impedance of a trumpet after modal analysis (red), original measured impedance (dashed black), difference between reconstructed and measured (solid black).

\section{Numerical continuation method}

Numerical continuation methods allow to follow solutions of a nonlinear dynamical system with respect to a parameter of the system. Also refereed to as "path-following methods", they allow computation of branches of solutions of the system instead of a single solution point. Different continuation methods exist, based on different approaches for the computation of the solution branches (AUTO, MANLAB) 31, 32. In this work, we choose to work with the Asymptotic Numerical Method (ANM) 33] implemented in the software MANLAB [32]. This method is based on the expansion of the solutions under the form of truncated Taylor series, providing analytical formulations of the branch of solution. 

nonlinearities. The complete model considered can be written as follows:

$$
\left\{\begin{array}{l}
\ddot{y}(t)+\frac{\omega_{l}}{Q_{l}} \dot{y}(t)+\omega_{l}^{2}\left(y(t)-y_{0}\right)=\frac{1}{\mu_{l}}\left(p_{0}-p(t)\right) \\
R_{k}=\Re\left(\dot{p}_{k}(t)\right)=\Re\left(Z_{c} C_{k} u(t)+s_{k} p_{k}(t)\right), \forall k \in[1, N] \\
I_{k}=\Im\left(\dot{p}_{k}(t)\right)=\Im\left(Z_{c} C_{k} u(t)+s_{k} p_{k}(t)\right), \forall k \in[1, N]
\end{array}\right.
$$

with $p(t)=2 \sum_{k=1}^{N} \Re\left(p_{k}(t)\right)$ and $u=\sqrt{\frac{2\left|p_{0}-p\right|}{\rho}} b \cdot \operatorname{sign}\left(p_{0}-p\right) \cdot \theta(y)$, and $\theta(y)=\frac{|y|+y}{2}$.

This system of equations can be made dimensionless by introducing the following variables:

$$
\left\{\begin{array}{l}
x=\frac{y}{y_{0}} \\
P_{M}=\mu_{l} \omega_{l}^{2} y_{0} \\
\gamma=\frac{p_{0}}{P_{M}} \\
\tilde{p}=\frac{p}{P_{M}} \\
\tilde{R}_{k}=\frac{R_{k}}{P_{M}} \\
\tilde{I}_{k}=\frac{I_{k}}{P_{M}} \\
\tilde{u}=u \frac{Z_{c}}{P_{M}} \\
\tilde{v}=\frac{v}{\sqrt{2 P_{M} / \rho}} \\
\zeta=Z_{c} b y_{0} \sqrt{\frac{2}{\rho P_{M}}} \\
\tilde{t}=t \Im\left(s_{1}\right) \\
\tilde{\omega}_{l}=\frac{\omega_{l}}{\Im\left(s_{1}\right)} \\
\tilde{C}_{k}=\frac{C_{k}}{\Im\left(s_{1}\right)} \\
\tilde{s}_{k}=\frac{s_{k}}{\Im\left(s_{1}\right)} .
\end{array}\right.
$$

The following dimensionless system is then obtained: 


$$
\left\{\begin{array}{l}
\dot{\tilde{R}}_{k}=\Re\left(\tilde{C}_{k} \tilde{u}+\tilde{s}_{k} \tilde{p}_{k}\right), \forall k \in[1, N] \\
\dot{\tilde{I}}_{k}=\Im\left(\tilde{C}_{k} \tilde{u}+\tilde{s}_{k} \tilde{p}_{k}\right), \forall k \in[1, N] \\
\frac{1}{\tilde{\omega}_{l}} \tilde{\dot{x}}=\tilde{z} \\
\frac{1}{\tilde{\omega}_{l}} \tilde{\dot{z}}=\left(1-x-\frac{1}{Q_{l}} \tilde{z}+\gamma-\tilde{p}\right),
\end{array}\right.
$$

with $\tilde{p}=2 \sum_{k=1}^{N} \Re\left(\tilde{p}_{k}\right), \tilde{u}=\zeta \frac{(|x|+x)}{2} \tilde{v}$ and $\tilde{v}=\sqrt{|\gamma-\tilde{p}|} \cdot \operatorname{sign}(\gamma-\tilde{p})$.

The nonlinearities in $\tilde{v}$ is treated as follows [39]:

$$
\tilde{v}|\tilde{v}|=\gamma-\tilde{p}
$$

Moreover, the absolute values can be handled by considering auxiliary variables $w \simeq|\tilde{v}|$ and $s \simeq|x|$, and regularizing the absolute values using hyperbolic functions such as:

$$
\left\{\begin{array}{l}
w^{2}=\tilde{v}^{2}+\epsilon_{v} \\
s^{2}=x^{2}+\epsilon_{x}
\end{array}\right.
$$

with $0<\epsilon_{v}<<1$ and $0<\epsilon_{x}<<1$, the regularization constants. In the following, $\epsilon_{v}=\epsilon_{x}=10^{-3}$.

The final system then writes as follows:

$$
\left\{\begin{array}{l}
\dot{\tilde{R_{k}}}=\Re\left(\tilde{C}_{k}\right) \tilde{u}+\Re\left(\tilde{s}_{k}\right) \tilde{R}_{k}-\Im\left(\tilde{s}_{k}\right) \tilde{I}_{k}, \forall k \in[1, N] \\
\dot{\tilde{I_{k}}}=\Im\left(\tilde{C}_{k}\right) \tilde{u}+\Im\left(\tilde{s}_{k}\right) \tilde{R}_{k}+\Re\left(\tilde{s}_{k}\right) \tilde{I}_{k}, \forall k \in[1, N] \\
\tilde{\dot{x}}=\tilde{\omega}_{l} \tilde{z} \\
\tilde{\dot{z}}=\tilde{\omega}_{l}\left(1-x-\frac{1}{Q_{l}} \tilde{z}+\gamma-\tilde{p}\right),
\end{array}\right.
$$

with the auxilary equations:

$$
\left\{\begin{array}{l}
0=2 \sum_{k=1}^{N} \tilde{R}_{k}-\tilde{p} \\
0=x^{2}+\epsilon_{x}-s^{2} \\
0=\gamma-\tilde{p}-\tilde{v} w \\
0=\tilde{v}^{2}+\epsilon_{v}-w^{2} \\
0=\zeta \frac{(s+x)}{2} \tilde{v}-\tilde{u} .
\end{array}\right.
$$

Equations in systems 13 and 14 constitutes the final form of dimensionless and quadratic model implemented in MANLAB. 


\section{Results}

\section{A Results for one trumpet}

One of the main difficulties in applying the physical model is the choice of the parameter values of the lip model. Following recent literature on the subject [17, we choose the following values of the physical parameters:

$$
\left\{\begin{array}{l}
Q_{l}=3 \\
\mu_{l}=2 \mathrm{~kg} \cdot \mathrm{m}^{-2} \\
y_{0}=0.1 \mathrm{~mm} \\
b=8 \mathrm{~mm}
\end{array}\right.
$$

\section{Linear Stability Analysis}

The natural frequency of the lips $\omega_{l}$ is estimated by Linear Stability Analysis (LSA) so that the excited regime is a $\mathrm{Bb} 4\left(f_{0} \simeq 470 \mathrm{~Hz}\right)$, and the mouth pressure at the oscillation threshold is minimum. The top plot of Fig. 6 represents the mouth pressure at oscillation threshold, $p_{0_{\text {min }}}$, with respect to the lip natural frequency $f_{l}$, obtained by LSA. The bottom part of the figure represents the frequency of the periodic regime at the threshold. For the $\mathrm{Bb} 4$ regime (corresponding to the 4th peak of the input impedance), the threshold pressure follows a "U-shaped" curve with a local minimum. We consider that this local minimum corresponds to a "sweet spot" where the player will preferably try to play at onset (point of minimal blowing pressure). Indeed we may reasonably expect the player to adapt his/her embouchure (lip parameters) in order to minimize the blowing static pressure he/she has to produce to produce sound. We then choose the corresponding lip natural frequency for the rest of the calculations. Note that this assumption (constant lip frequency from sweet spot) is certainly an important simplification of the reality; for a same note, players may vary the lip natural frequency with dynamics, timbre, intonation, etc. However for the sake of simplifying this complex problems, and with the goal of comparing instruments, we follow this assumption and procedure for all instruments.

\section{Continuation of periodic branches}

Figure 7 represents the bifurcation diagram (peak-to-peak amplitude of $p$ with respect to $p_{0}$ ), of the periodic branch of solution obtained for a Bb4 for trumpet A, obtained by the Asymptotic Numerical Method using MANLAB. For this trumpet, the lip natural frequency is set as defined previously to $f_{l}=\omega_{l} / 2 \pi=382.18 \mathrm{~Hz}$. As expected for an outward-striking lip model, the lip natural frequency is smaller than the oscillation frequency of the corresponding regime 2. Some markers indicate specific landmarks: the Hopf bifurcation point $(\bigcirc)$, the fold $(\nabla)$, the amplitude of $p$ at the Hopf bifurcation $(\triangle)$ and at a $5 \mathrm{kPa}$ reference for $p_{0}(\square)$. This reference value of $5 \mathrm{kPa}$ is considered as a reasonable upper limit for $\mathrm{Bb} 4$ as measured in trumpet players' mouth [39.40]. The values of $p$ and $p_{0}$ are derived from dimensionless variables as follows: 
Fréour et al., p. 11
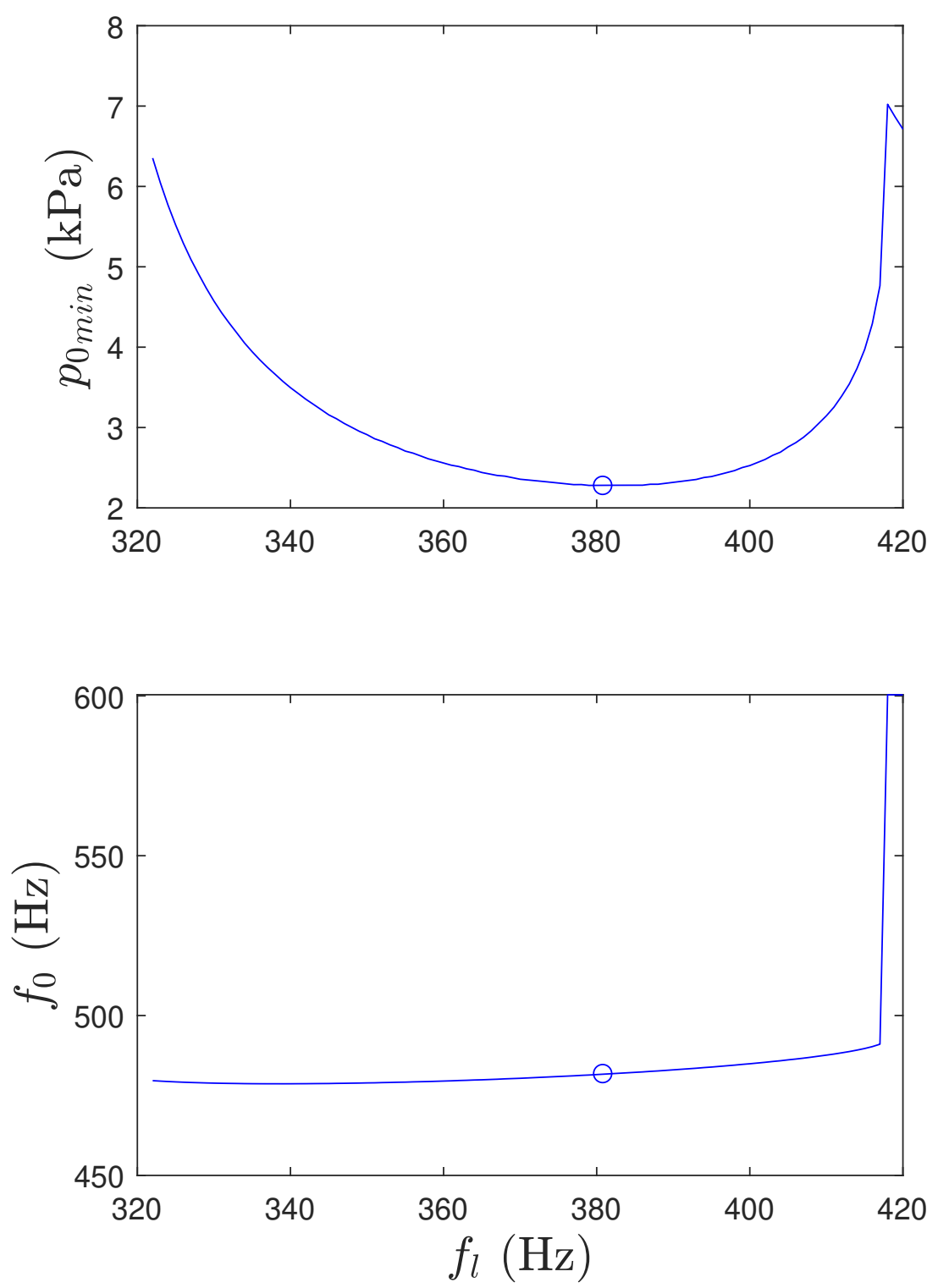

Figure 6: (Color online) Results from Linear Stability Analysis applied to trumpet A for the fourth regime $(\mathrm{B} b 4)$ : linear threshold pressure (top), fundamental frequency at threshold (bottom). The circle indicates the local minimum in threshold pressure for this regime, found for $f_{l}=382.18 \mathrm{~Hz}$.

$$
\left\{\begin{array}{l}
p=\tilde{p} \cdot P_{M} \\
p_{0}=\gamma \cdot P_{M}
\end{array}\right.
$$

A Hopf bifurcation appears around $p_{0}=2.2 \mathrm{kPa}$. The bifurcation diagram shows an inverse bifurcation with a first part of the branch going on the left of the diagram and being unstable until it reaches a fold. This fold is characterized by a change of stability towards a stable section that evolves almost linearly with the static mouth pressure $p_{0}$. 
Fréour et al., p. 12

This type of behavior is not surprising for a brass instrument. Indeed, the inverse bifurcation induces an hysteresis that brass players are usually familiar with: it is easier to play a very quiet sound by decreasing $p_{0}$ while a sustained regime is already established, rather than starting a note very quietly. Another way to interpret this result is to consider a crescendo-decrescendo maneuver (sustained note with increase and decrease of loudness). The path followed by the musician in the bifurcation diagram is shown in Figure 8 After reaching the Hopf point at $p_{0}=2.2 \mathrm{kPa}$, the musician "jumps" on the stable periodic branch where sound starts $(|p|>0)$. The musician can increase loudness by increasing the static mouth pressure $p_{0}$. When decreasing $p_{0}$ the musician follows the same branch in opposite direction, down to the fold, and is therefore able to reach a smaller dynamic (loudness) than in the early crescendo phase (hysteresis phenomenon). If the musician further decreases the mouth pressure, sound will stop since there is no stable periodic branch below that fold point.

From this output from continuation it is possible to define some descriptors that characterize important features of the obtained bifurcation diagram:

- The "amplitude of the hysteresis" $H$ is defined as the horizontal distance between the $\nabla$ and $\triangle$ landmarks. This quantity is linked to the playing phenomenon explained above, that can be also interpreted as the difference between onset and offset pressures (mouth pressure and internal acoustic pressure).

- The "dynamic range" $D$ is defined as the vertical distance between the $\nabla$ and $\square$ landmarks. It reflects how much the internal sound pressure can vary when the player produces a blowing pressure up to $5 \mathrm{kPa}$.

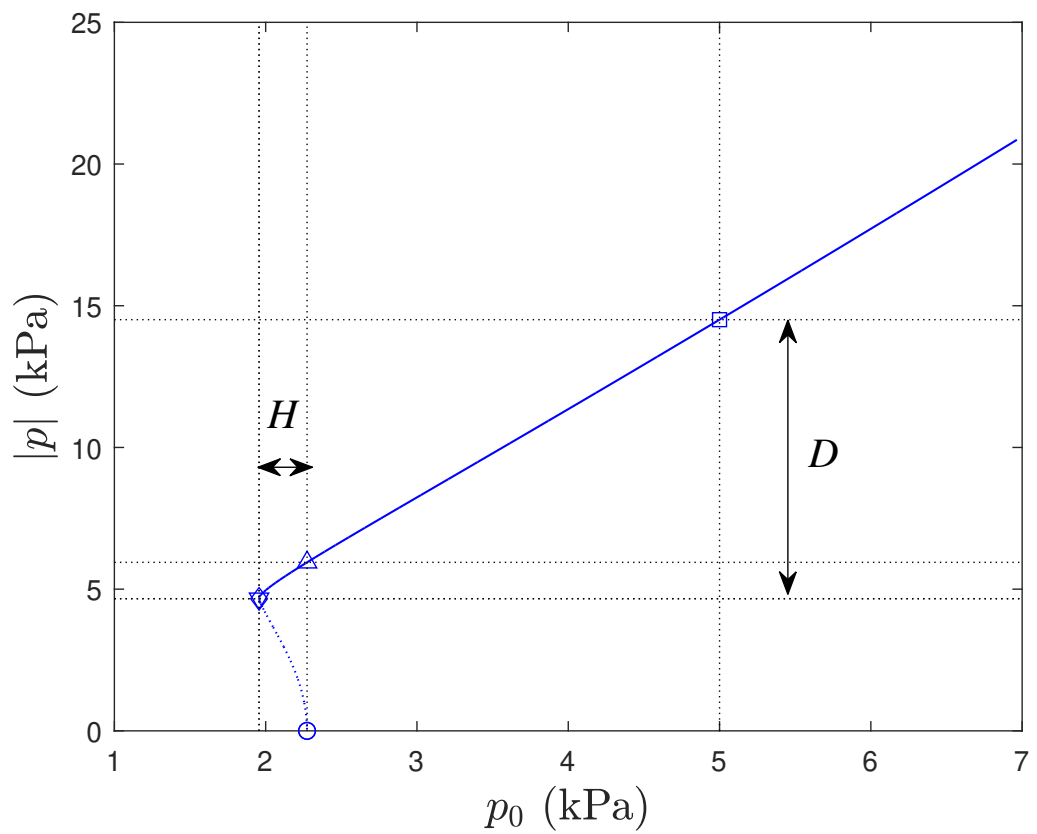

Figure 7: (Color online) Bifurcation diagram (peak-to-peak amplitude of $p$ with respect to $p_{0}$ ) of the periodic branch of solution for a $\mathrm{Bb} 4(470 \mathrm{~Hz})$. The dotted line indicates the unstable part of the solution branch, while the solid line indicates the stable part of the branch. $\bigcirc$ : Hopf bifurcation, $\nabla$ : fold, $\triangle:|p|$ at the Hopf bifurcation, $\square:|p|$ at $5 \mathrm{kPa}$. 


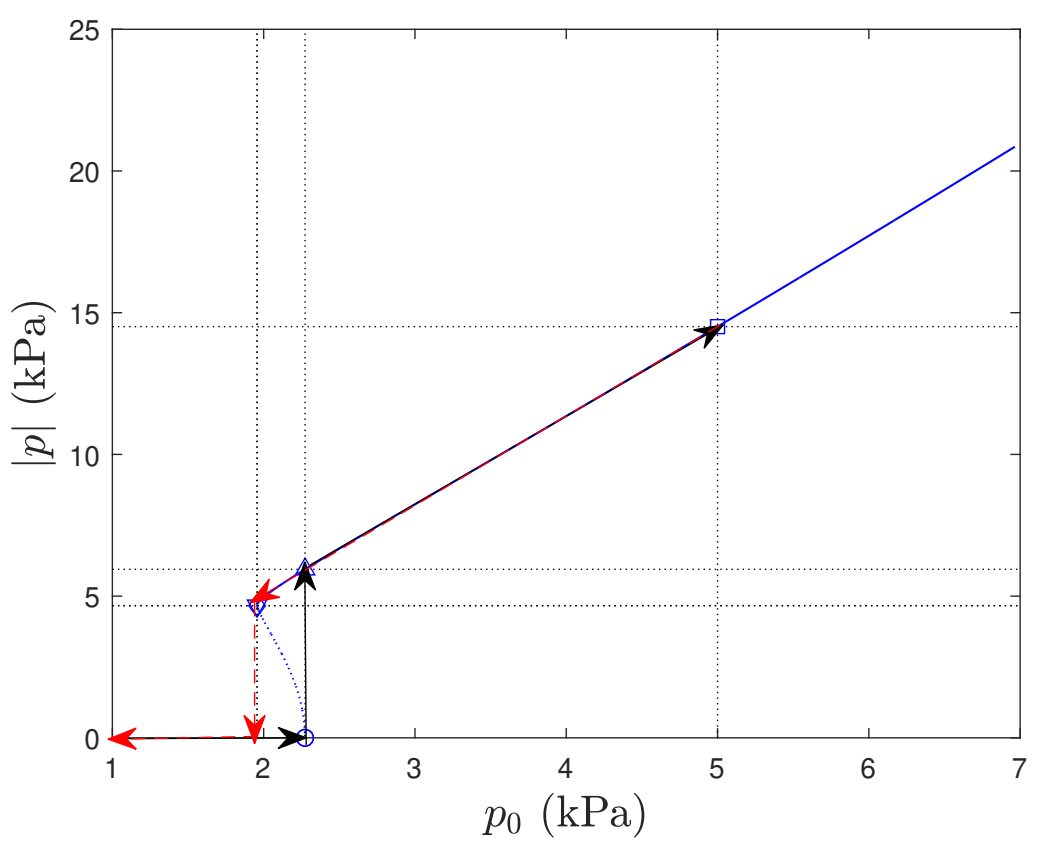

Figure 8: (Color online) Path followed by the musician during a slow crescendo-decrescendo. Black arrows: crescendo phase. Red arrows: decrescendo phase. This figure illustrates the fact that the smallest loudness can be achieved at the end of a decrescendo (hysteresis phenomenon).

\section{B Results for multiple trumpets}

The main objective ot this work is to compare different $\mathrm{B} b$ trumpets on the basis of results obtained by continuation. The reconstructed input impedance (after modal analysis) of the eight trumpets considered in this study are represented in Fig. 9. These eight trumpets are all different high-end models chosen in the catalogs of three makers (five different models from a first maker, two different models from a second maker, one model from a third maker). The same mouthpiece was used for all impedance measurements. The tuning slides of the instruments were adjusted by blowing tests before the measurements. To illustrate the differences between instruments, the modal parameters of the fourth mode are given in Table 1 for each trumpet, where $s_{4}=-\alpha_{4}+j \omega_{4}$ with $\alpha_{4}$ the damping coefficient and $\omega_{4}$ the angular frequency of the $4^{\text {th }}$ acoustic mode. The mean and standard deviation of the modal parameters across trumpets are also provided in Table 1, shedding more light on the small variability in the modal parameters between the instruments. Furthermore, as shown in Fig. 10, reconstructed input impedances (from the modal parameters extracted by ESPRIT) transcribe very well the differences observed in the measurements. This confirms the precision of our measurements and modal analysis procedures for the purpose of this comparison.

The computation of the periodic branch of solution for a $\mathrm{B} b 4$ is performed for seven $\mathrm{B} b$ trumpets $(\mathrm{B}, \mathrm{C}, \mathrm{D}, \mathrm{E}$, F, G, H) in the same conditions as for trumpet A: the lip parameters are set to the same values, except for $\omega_{l}$ that is set to the "sweet spot" value identified by a preliminary LSA calculation, the modal parameters describing the input impedance of the instrument are adapted according to the trumpets. The values of $f_{l}=\omega_{l} / 2 \pi$ are given 


\begin{tabular}{l|c|c|c|c} 
& $\begin{array}{c}\alpha_{4} \\
\left(\mathrm{~s}^{-1}\right)\end{array}$ & $\begin{array}{c}f_{4}=\frac{\omega_{4}}{2 \pi} \\
(\mathrm{Hz})\end{array}$ & $\begin{array}{c}\left|C_{4}\right| \\
\left(\mathrm{Pa} . \mathrm{m}^{-3}\right)\end{array}$ & $\begin{array}{c}f_{l}=\frac{\omega_{l}}{2 \pi} \\
(\mathrm{Hz})\end{array}$ \\
\hline \hline TP A (1) & 34.02 & 462.98 & 2445.2 & 382.18 \\
TP A (2) & 34.14 & 463.75 & 2451.6 & 382.38 \\
\hline TP B (1) & $\mathbf{3 4 . 0 5}$ & $\mathbf{4 6 3 . 5 0}$ & $\mathbf{2 2 8 5 . 3}$ & $\mathbf{3 7 7 . 9 5}$ \\
TP B (2) & $\mathbf{3 3 . 9 9}$ & $\mathbf{4 6 3 . 4 8}$ & $\mathbf{2 2 8 1 . 9}$ & $\mathbf{3 7 7 . 7 5}$ \\
\hline TP C (1) & 33.96 & 462.80 & 2252.7 & 377.31 \\
TP C (2) & 33.93 & 462.51 & 2254.1 & 376.94 \\
\hline TP D (1) & $\mathbf{3 4 . 3 0}$ & $\mathbf{4 6 4 . 2 1}$ & $\mathbf{2 3 6 1 . 0}$ & $\mathbf{3 8 0 . 9 7}$ \\
TP D (2) & $\mathbf{3 4 . 3 6}$ & $\mathbf{4 6 4 . 5 8}$ & $\mathbf{2 3 6 9 . 9}$ & $\mathbf{3 8 1 . 0 9}$ \\
\hline TP E (1) & 34.33 & 466.15 & 2409.2 & 381.07 \\
TP E (2) & 34.04 & 466.01 & 2399.4 & 380.85 \\
\hline TP F (1) & $\mathbf{3 4 . 9 7}$ & $\mathbf{4 6 7 . 5 5}$ & $\mathbf{2 4 8 9 . 7}$ & $\mathbf{3 8 5 . 0 9}$ \\
TP F (2) & $\mathbf{3 5 . 0 4}$ & $\mathbf{4 6 7 . 5 3}$ & $\mathbf{2 4 9 2 . 2}$ & $\mathbf{3 8 5 . 0 8}$ \\
\hline TP G (1) & 34.82 & 466.38 & 2381.5 & 382.36 \\
TP G (2) & 34.80 & 466.08 & 2383.8 & 382.15 \\
\hline TP H (1) & $\mathbf{3 3 . 8 6}$ & $\mathbf{4 6 4 . 3 9}$ & $\mathbf{2 2 1 6 . 3}$ & $\mathbf{3 7 7 . 4 3}$ \\
TP H (2) & $\mathbf{3 3 . 7 5}$ & $\mathbf{4 6 3 . 3 4}$ & $\mathbf{2 2 2 2 . 4}$ & $\mathbf{3 7 6 . 9 2}$ \\
\hline \hline MEAN & 34.27 & 464.70 & 2356.0 & 380.47 \\
STD & 0.41 & 1.67 & 92.66 & 2.77
\end{tabular}

Table 1: Modal parameters for the fourth mode of the input impedance of each trumpet, lip natural frequency at "sweet spot" obtained by LSA. The last two rows indicate the mean and standard deviation across trumpets.
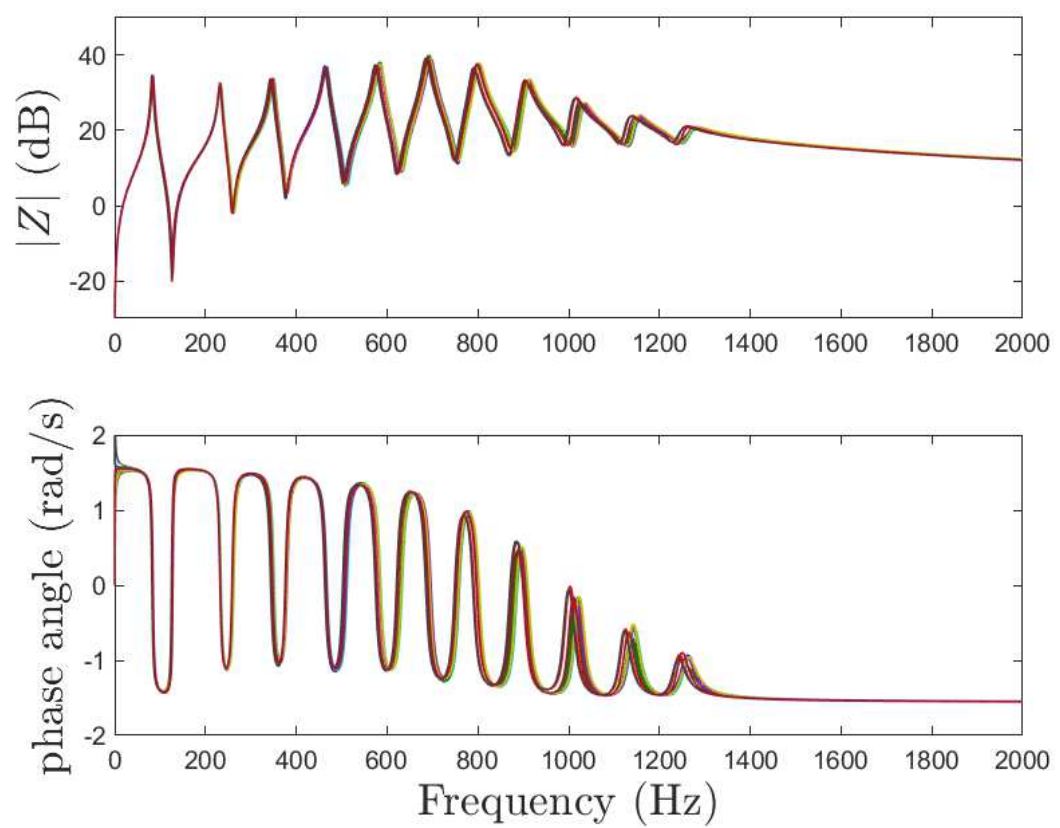

Figure 9: (Color online) Reconstructed input impedance of the eight trumpets analyzed.

in Table 1. The obtained bifurcation diagrams are presented in Fig. 11. For each trumpet, two calculations are performed from two repetitions of the impedance measurement, performed non-consecutively. This aims at performing a basic check that the variability in the impedance measurements is smaller than the variability across instruments. 

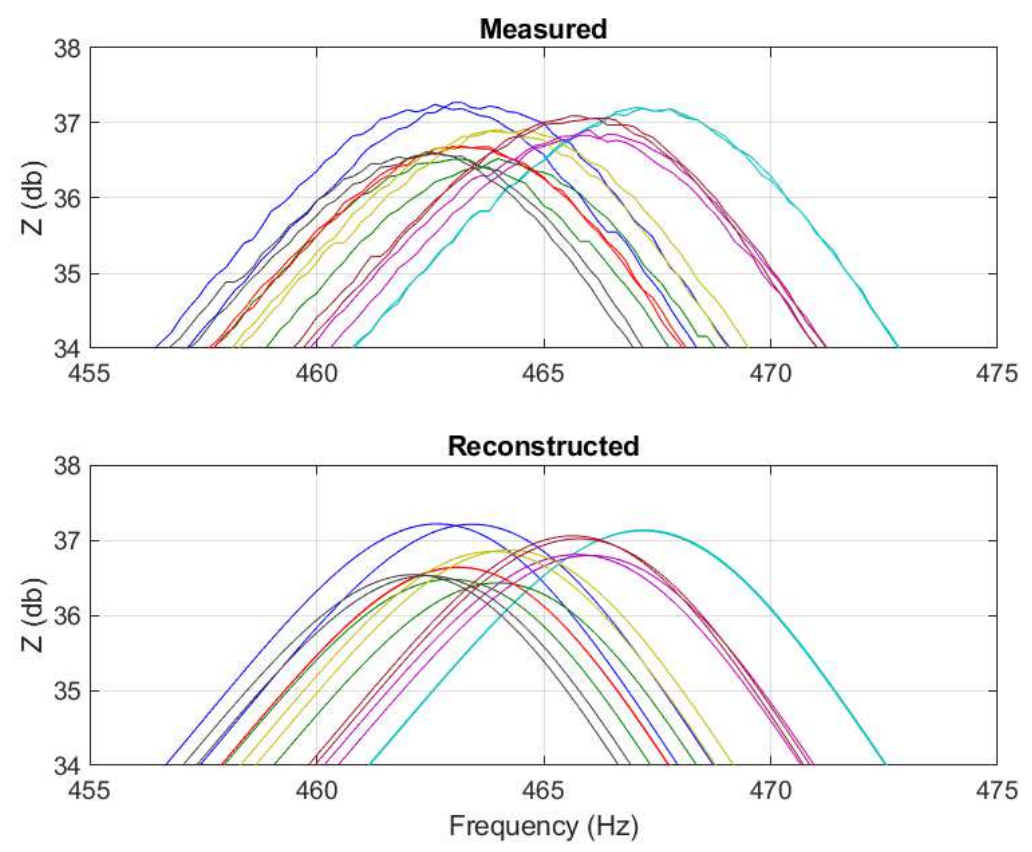

Figure 10: (Color online) Zoom on the fourth peak of the input impedance of the eight trumpets. Measured (top) and reconstructed from extracted modal parameters (bottom).

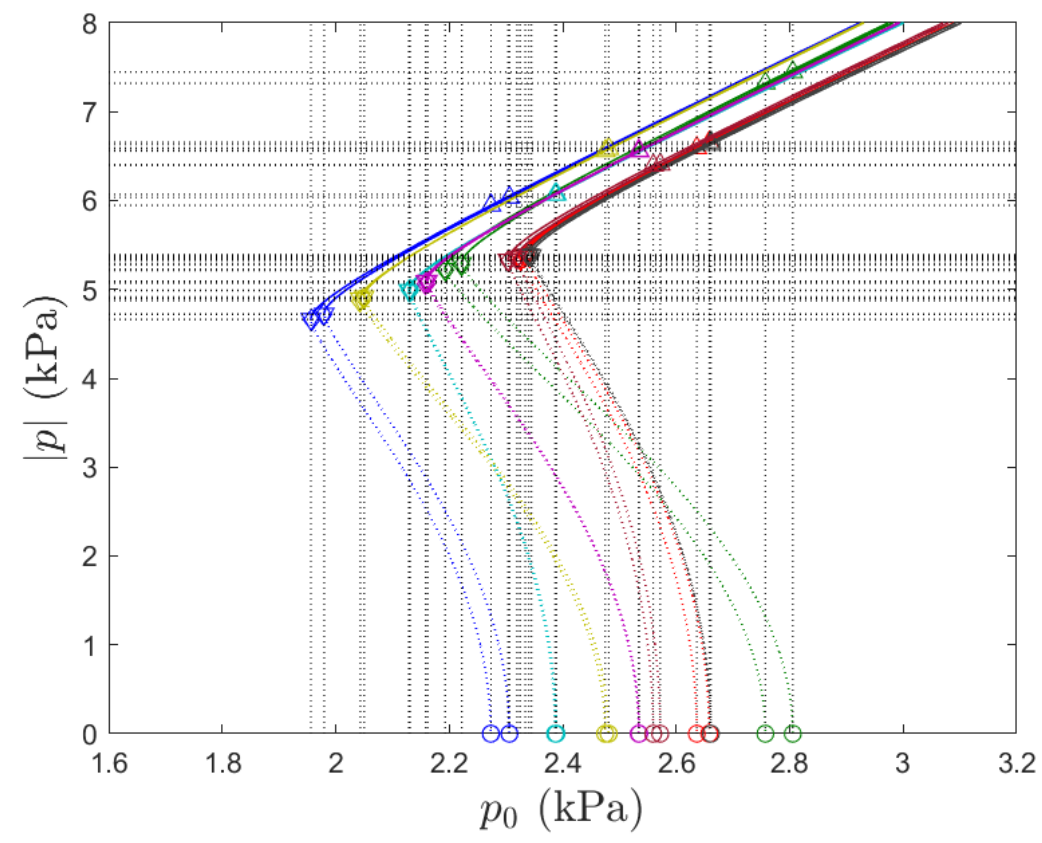

Figure 11: (Color online) Bifurcation diagram (peak-to-peak amplitude of $p$ with respect to $p_{0}$ ) of the periodic branch of solution for a $\mathrm{B} b 4(470 \mathrm{~Hz})$ and for 8 trumpets (two impedance data for each trumpet).

Differences between the different trumpets can be observed in the bifurcation diagrams represented in Fig. 11 . These are visible at the different landmarks: Hopf point, fold, and location of the periodic branch, although some instruments show almost overlapping periodic branches. The hysteresis $H$ and dynamic range $D$ are 
extracted for each diagram.

Each trumpet analyzed is represented by two dots in the $2 \mathrm{D}$ space formed by these two descriptors. The result is presented in Fig. 12. The variability in the impedance within each trumpet is small enough so that clear differences appear between the instruments in this two-dimensional space. Variations across trumpets are about $58 \%$ of the maximum value for $H$ (comprised between 0.25 and $0.59 \mathrm{kPa}$ ) and $14 \%$ of the maximum value for $D$ (comprised between 8.4 and $9.8 \mathrm{kPa}$ ). From the performance perspective, we may conjecture that an instrument on the top-right corner will show larger sensitivity to blowing pressure in terms of dynamics and important difference between onset and offset pressures, while an instrument on the bottom left will be less sensitive to mouth pressure and present less difference between onset and offset pressures. Note that the question of the threshold of perceptible differences by trumpet players is beyond the scope of this study.

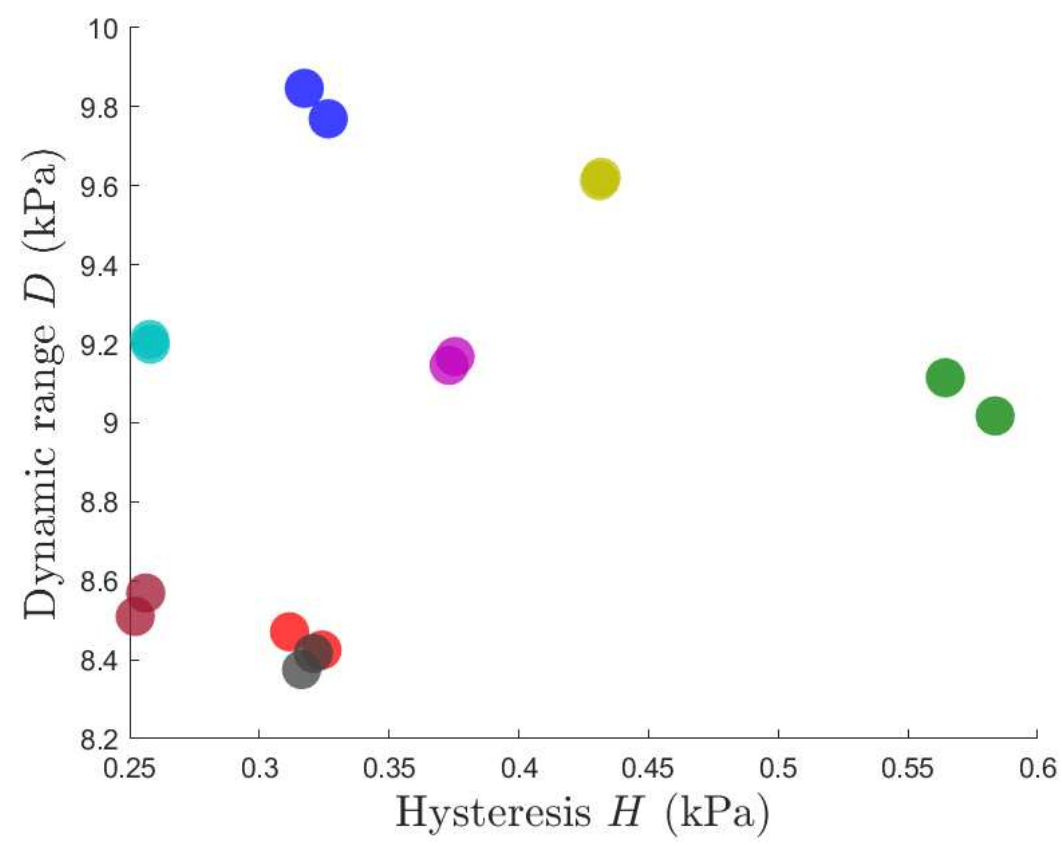

Figure 12: (Color online) Clustering of 8 trumpets (two impedance data for each trumpet) in the space $(H, D)$ for a $\mathrm{B} b 4(470 \mathrm{~Hz})$, obtained from bifurcation diagrams.

\section{Sensitivity of the results to lip parameters}

In brass instruments, the excitation mechanism relies on the vibrations of the lips of the players, that is on human tissues, with shape and mechanical properties likely to vary from one player to another. The issue of generalizing these numerical results to other embouchure configurations is therefore important in order to confirm the calculated differences between instruments.

As explained in previous sections, the results of Fig. 12 are obtained for a same set of values of the lip parameters $\left(Q_{l}, \mu_{l}, y_{0}, b\right)$. The physical model constructed is non linear, there is therefore no guarantee that the calculated differences between instruments are robust to variations of the lip parameters. To address this 
issue, 20 "virtual players", each defined by a set of lip parameters, are generated by random variations of $\left\{Q_{l}, \mu_{l}, \quad{ }^{247}\right.$ $\left.y_{0}\right\}$ within $\pm 10 \%$ of the values used in previous section ( $\pm 10 \%$ is expected to represent inter-player variability), while $\left\{b, \omega_{l}\right\}$ are kept constant. Figure 13 illustrates the dispersion of the lip-parameter values for the 20 virtual players.

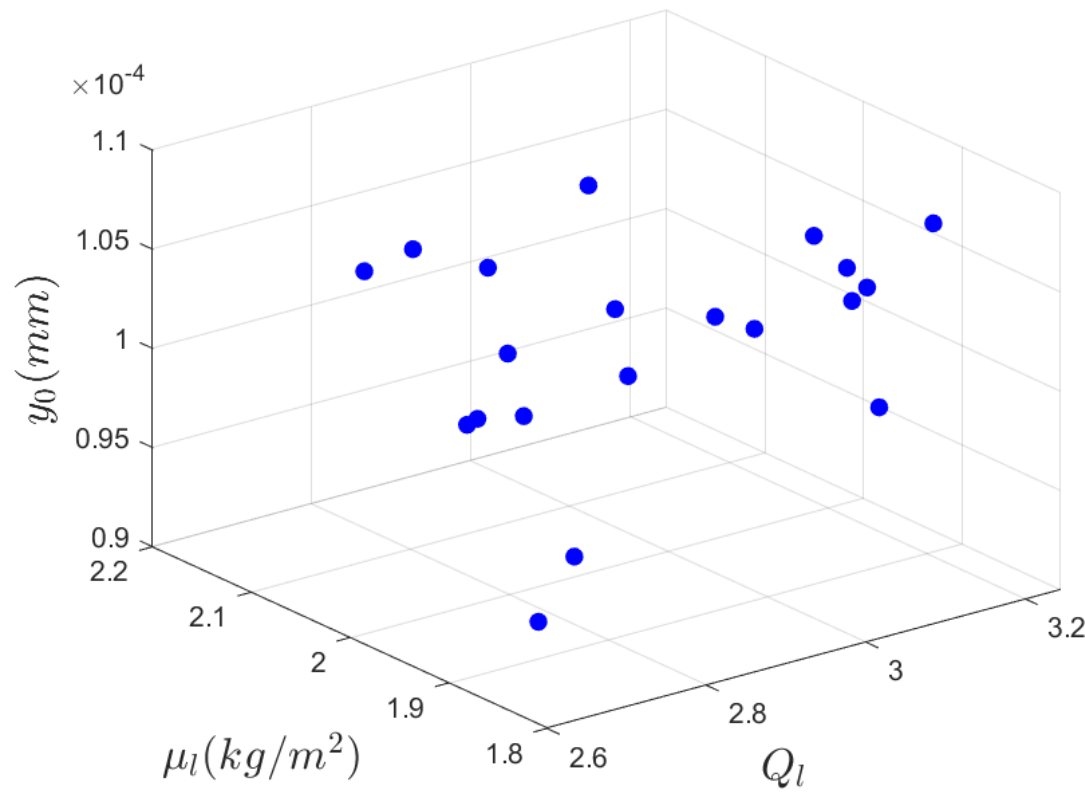

Figure 13: (Color online) Lip model parameters $\left\{Q_{l}, \mu_{l}, y_{0}\right\}$ of the 20 virtual players generated.

Each virtual player is applied to each impedance and the corresponding bifurcation diagram is calculated in the same conditions as in previous section. For illustration, all the diagrams obtained are represented in Fig. 14. The hysteresis $H$ and dynamic range $D$ are extracted for each diagram and used to locate each result in a two-dimensional space. For each impedance, the means of $H$ and $D$ are calculated across the 20 virtual players. The results are plotted in Fig. 15 and 16, where the transparent dots indicate the results from each diagram, and the plain dots correspond to the means across the virtual players for each impedance. In Fig. 15, although the clouds for each trumpet have roughly the same shape, they appear distorted in different ways depending on the instruments. They are also "centered" at different locations for each instrument. The differences in the mean values are clearly visible in Fig. 16.

Introducing variability in the lip parameters leads to variations of $H$ of $94 \%$ of the maximum value, and variations of $D$ of $43 \%$ of the maximum value.

A zoom on the mean values obtained is presented in Fig. 17. The cluster obtained is qualitatively very similar to the one of Fig. 12 obtained with a single set of lip parameters: the values of $H$ remain within 0.31 and $0.71 \mathrm{kPa}$ that is a variation of $56 \%$ of the maximum value, while the values of $D$ are found within 8.0 and $9.6 \mathrm{kPa}$, that is a variation of $17 \%$ of the maximum value.

Therefore, one can say the cluster provided by the mean values agrees with the calculation of previous section 


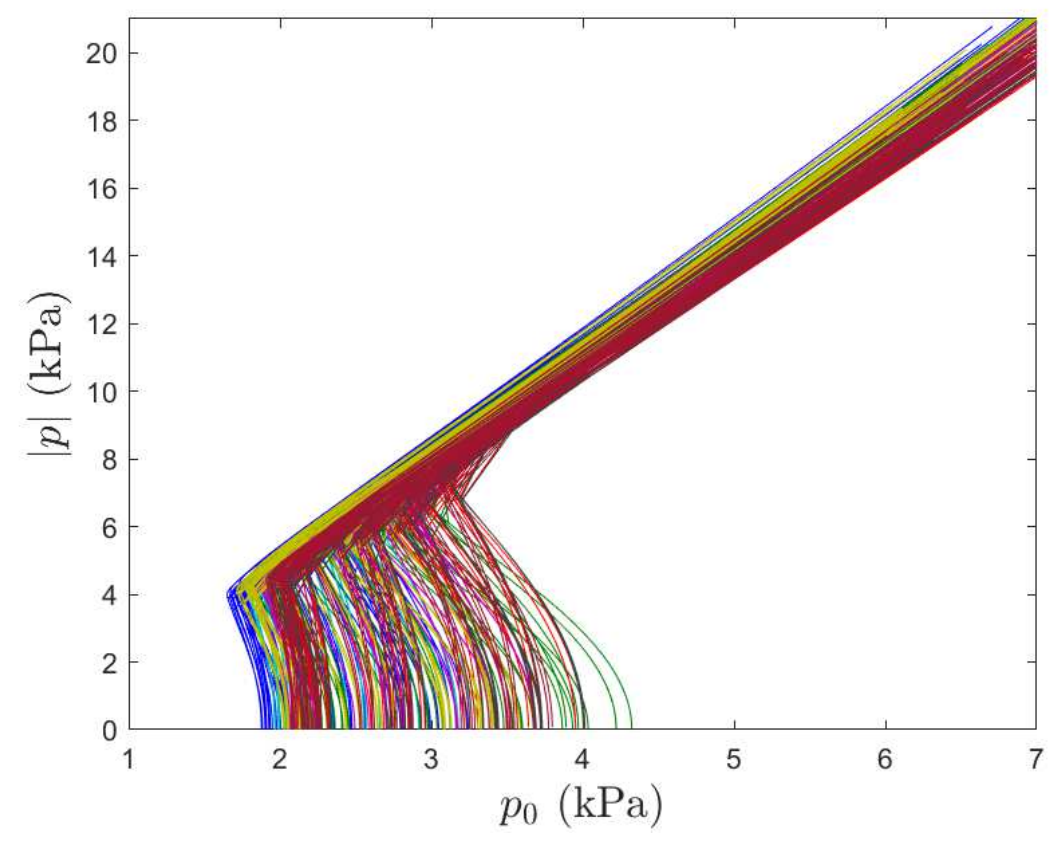

Figure 14: (Color online) Bifurcation diagrams (peak-to-peak amplitude of $p$ with respect to $p_{0}$ ) of the periodic branch of solution for a $\mathrm{B} b 4(470 \mathrm{~Hz})$, for 20 virtual players applied to 8 trumpets (two impedance data for each trumpet). For faster computation, the stability of the branches was not computed.

with a single set of lip parameters. This supports the hypothesis that the obtained trumpet categorization is robust to the variations of the lip parameters in this space of descriptors. In other words, the numerical categorization obtained by our procedure seems dominated by the influence of the trumpets, and not dependent on the lip parameters.

\section{Discussion and conclusions}

Understanding differences perceived by players between different instruments with slight design variations is a difficult problem. What we can call a "hybrid" physical model", where modal parameters extracted from a measurement of the instrument input impedance are used as input of the model, might contribute to solve this question. Indeed, some advanced numerical methods provide attractive tools to analyze in depth the dynamical system formed by the \{player - instrument $\}$ model, and extract information that we hope to be more closely related to the performance of the instrument.

In this study, we combined and adapted different technologies (High Resolution modal analysis, Linear Stability Analysis, numerical continuation by HBM and ANM) in order to build and analyze a physical model of trumpet in different configurations. The application of the ANM, to our knowledge one of the first to a brass instrument model after the work of Velut 39], allows to calculate bifurcation diagrams from which descriptors (hysteresis and dynamic range) related to the performance of the instrument can be extracted. Although a simple model of the lips is considered (one degree of freedom, no model of contact between the lips), the different 

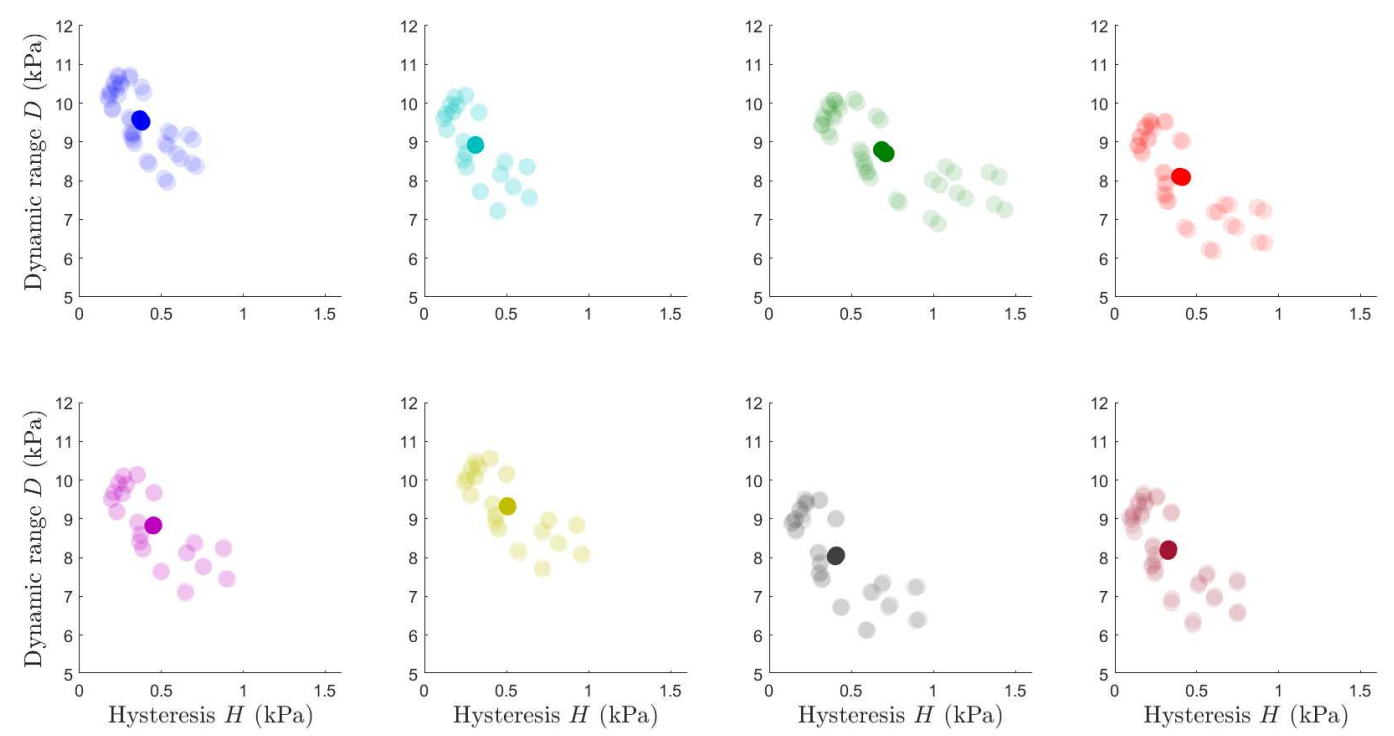

Figure 15: (Color online) Clusterings obtained from 20 virtual players applied to 8 trumpets (two impedance data for each trumpet and one plot per trumpet) in the space $(H, D)$ for a $\mathrm{B} b 4(470 \mathrm{~Hz})$. Transparent dots: results extracted from each diagram. Plain dots: means calculated across the virtual players for each impedance data.

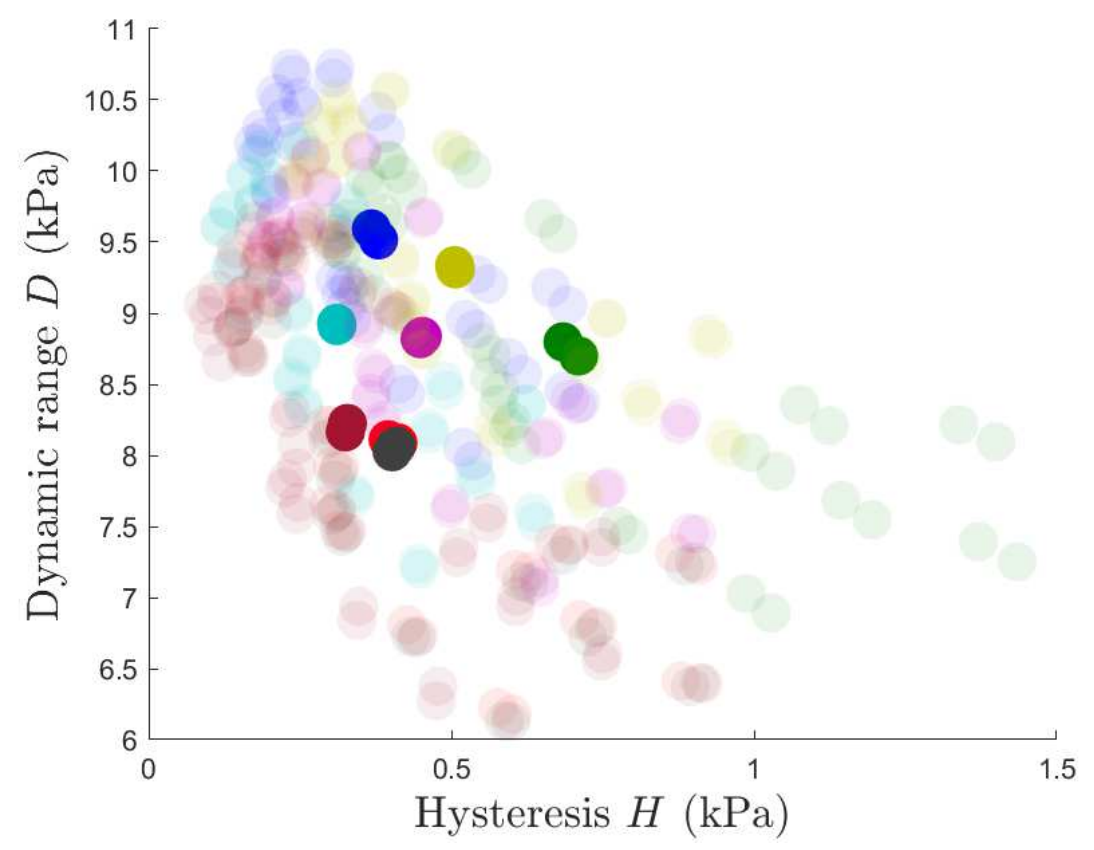

Figure 16: (Color online) Clustering obtained from 20 virtual players applied to 8 trumpets (two impedance data for each trumpet) in the space $(H, D)$ for a $\mathrm{B} b 4(470 \mathrm{~Hz})$ and gathered in the same figure. Transparent dots: results extracted from each diagram. Plain dots: means calculated across the virtual players for each impedance data. Same data as in Fig. 15.

trumpets examined in this study can then be differentiated in the space of these descriptors, showing the ability of the method to identify consistent differences between instruments. 


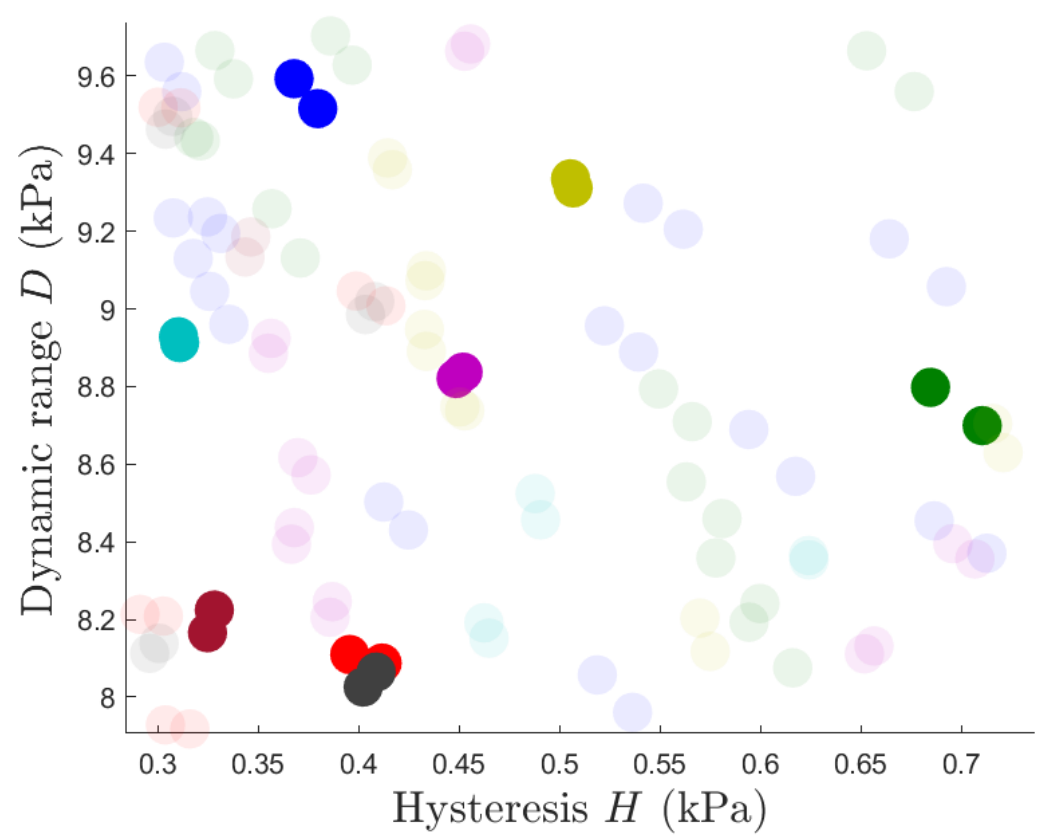

Figure 17: (Color online) Zoom on Fig 16

In order to account for variability in the control between players, at the level of the lip embouchure in particular, calculations were performed for a range of values of the lip model parameters. The results confirmed the categorization obtained with one set of parameters, and therefore support the hypothesis that the obtained categorization of the instruments is primarily determined by the impedance.

This type of outcome may be of interest for a musical instrument maker. Indeed, although it is applied to a single regime of oscillation here, it allows to clarify and quantify differences between instruments on the basis of numerical indicators related to the performance of the instrument. In the process of designing a new trumpet with a new geometry, the proposed analysis can be conducted from a calculation of the impedance, and the new instrument compared to existing instruments using this numerical approach.

From the point of view of the perception of real players, these numerical indicators may be easier to correlate with perceptual evaluations conducted with human players. More specifically, in this article we suggested that the hysteresis could be associated to the difference between onset and offset pressures, while the dynamic range could be correlated to the actual dynamic range for that note. These hypotheses could be the starting point of a future work.

Regarding comparison with experiment, another challenge is to validate the obtained categorization experimentally, using an artificial player system for instance. At first by comparison of the calculated bifurcation diagrams with measurements performed with slow variation of the mouth pressure $p_{0}$, then by comparing the categorizations of trumpets obtained numerically and experimentally.

Finally, extending this approach to more notes, to be able to obtain a more global view at the beheaviour of instruments is definitely part of the next plans. 


\section{References}

[1] S. J. Elliot and J. M. Bowsher. Regeneration in brass instruments. Journal of Sound and Vibration, 307 $83(2): 181-217,1982$.

[2] M. Campbell. Brass instruments as we know them today. Acta Acustica united with Acustica, 90:600-610, 309 2004.

[3] A. Chaigne and J. Kergomard. Acoustique des instruments de musique. Belin, Paris, 2008.

[4] N. H. Fletcher. Autonomous vibration of simple pressure-controlled valve in gas flows. J. Acoust. Soc. 312 Am., 93(4):2172-2180, 1993.

[5] S. Adachi and M. A. Sato. Time-domain simulation of sound production in the brass instrument. J. Acoust. Soc. Am., 97(6):3850-3861, 1995.

314

[6] J. S. Cullen, J. Gilbert, and D. M. Campbell. Brass instruments: Linear stability analysis and experiments with an artificial mouth. Acta Acustica, 86:704-724, 2000.

[7] N. Lopes and T. Hélie. Energy balanced model of a jet interacting with a brass player's lip. Acta Acustica united with Acustica, 102:141-154, 2016.

[8] S. Adachi and M. A. Sato. Trumpet sound simulation using a two-dimensional lip vibration model. J. 320 Acoust. Soc. Am., 99(2):1200-1209, 1996.

[9] H. Boutin, N. Fletcher, J. Smith, and J. Wolfe. Relationships between pressure, flow, lip motion, and upstream and downstream impedances for the trombone. J. Acoust. Soc. Am., 137(3):1195-1209, 2015.

[10] T. Kaburagi, N. Yamada, T. Fukui, and E. Minamiya. A methodological and preliminary study on the acoustic effect of a trumpet player's vocal tract. J. Acoust. Soc. Am., 130(1):536-545, 2011.

[11] V. Fréour, N. Lopes, T. Hélie, R. Caussé, and G.P. Scavone. In-vitro and numerical investigations of the influence of a vocal-tract resonance on lip auto-oscillations in trombone performance. Acta Acustica united with Acustica, (101):256-269, 2015.

[12] S. Bilbao and J. Chick. Finite difference time domain simulation for the brass instrument bore. J. Acoust. Soc. Am., 134(5):3860-3871, 2013.

[13] H. Berjamin, B. Lombard, C. Vergez, and E. Cottanceau. Time-domain numerical modeling of brass instruments including nonlinear wave propagation, viscothermal losses, and lips vibration. Acta Acustica united with Acustica, 103:117-131, 2017.

[14] L. Maugeais and J. Gilbert. Nonlinear acoustic propagation applied to brassiness studies, a new simulation tool in the time domain. Acta Acustica united with Acustica, 103:67-79, 2017.

316

317

318

319 
[15] J. Saneyoshi, H. Tenamura, and S. Yoshikawa. Feedback oscillations in reed woodwind and brasswind instruments. Acustica, 67:194-210, 1987.

[16] F. Silva, Vergez C. Kergomard, J., and Gilbert J. Interaction of reed and acoustic resonator in clarinet-like systems. J. Acoust. Soc. Am., 124, 2008.

[17] L. Velut, C. Vergez, J. Gilbert, and M. Djahanbani. How well can linear stability analysis predict the behaviour of an outward-striking valve brass instrument model? Acta Acustica united with Acustica, 103:132-148, 2017.

[18] S. Karkar. Méthodes numériques pour les systèmes dynamiques non linéaires - Application aux instruments de musique auto-oscillants. PhD thesis, Université de Provence Aix-Marseille I, Marseille, France, 2012.

[19] C. Fritz and D. Dubois. Perceptual evaluation of musical instruments: State of the art and methodology. Acta Acustica united with Acustica, 101:369 - 381, 2015.

[20] B. Elie, F. Gautier, and B. David. Macro parameters describing the mechanical behavior of classical guitars. J. Acoust. Soc. Am., 132(6):4013-4024, 2012.

[21] H. Mansour, V. Fréour, C. Saitis, and G.P. Scavone. Post-classification of nominally identical steel-string guitars using bridge admittances. Acta Acustica united with Acustica, (101):394-407, 2015.

[22] V. Fréour, F. Gautier, B. David, and M. Curtit. Extraction and analysis of body-induced partials of guitar tones. J. Acoust. Soc. Am., 138(6):3930-3940, 2015.

[23] R. Tournemenne, J-F. Petiot, and J. Gilbert. The capacity for simulation by physical modeling to elicit perceptual differences between trumpet sounds. Acta Acustica united with Acustica, 102, 2016.

[24] Moore T.R., Gorman B.R., Rokni M., Kausel W., and Chatziioannou V. Axial vibrations of brass wind instrument bells and their acoustical influence: Experiments. J. Acoust. Soc. Am., 138(2):1233-1240, 2015.

[25] F. Silva. Émergence des auto-oscillations dans un instrument de musique à anche simple. $\mathrm{PhD}$ thesis, Université de Provence Aix-Marseille I, Marseille, France, 2009.

[26] C. A. Macaluso and J. P. Dalmont. Trumpet with near-perfect harmonicity: Design and acoustic results. J. Acoust. Soc. Am., 129(1):404-414, 2011.

[27] J. Gilbert, L.M. Leboso Ruiz, and S. Gougeon. Influence de la température sur la justesse d'un instrument à vent. In Proc. Bème Congrès Français d'Acoustique, pages 599-602, Tours, France, 2006.

[28] R. Roy and T. Kailath. Esprit: Estimation of signal parameters via rotational invariance techniques. IEEE Trans. Acoust. Speech, Signal Process., 37(7):984-995, 1989. 
[29] R. Badeau, B. David, and G. Richard. A new perturbation analysis for signal enumeration in rotational 365 invariance techniques. IEEE Trans. Signal Process., 54(2):450-458, 2006.

[30] K. Ege, X. Boutillon, and B. David. High resolution modal analysis. J. Sound Vib., 325:852-869, 2009.

[31] Auto. http://indy.cs.concordia.ca/auto/. Accessed: 2019-10-02.

[32] Manlab. http://manlab.lma.cnrs-mrs.fr/spip/. Accessed: 2019-10-02.

[33] B. Cochelin. A path following technique via an asymptotic-numerical method. Computers and Structures, 370 $53(5): 1181-1192,1994$.

[34] B. Cochelin and C. Vergez. A high order purely frequency-based harmonic balance formulation for continuation of periodic solutions. Journal of Sound and Vibration, 324:243-262, 2009.

[35] M.S. Nakhla and J. Vlach. A piecewise harmonic balance technique for determination of periodic response of nonlinear systems. IEEE Transactions on Circuit Theory, 23(2):85-91, 1976.

[36] J. Gilbert, J. Kergomard, and E. Ngoya. Calculation of the steady-state oscillations of a clarinet using the harmonic balance technique. J. Acoust. Soc. Am., 86(1):39-41, 1989.

[37] A. Lazarus and O. Thomas. A harmonic-based method for computing the stability of periodic solutions of 378 dynamical systems. Comptes Rendus Mécanique, 338(9):510-517, 2010.

[38] L. Guillot, B. Cochelin, and C. Vergez. A generic and efficient taylor series-based continuation method 380 using a quadratic recast of smooth nonlinear systems. International Journal of Numerical Methods in 381 Engineering, 119(4):261-280, 2019.

[39] L. Velut. Contrôle par le musicien des régimes d'oscillation des instruments de la famille des cuivres. $\mathrm{PhD} \quad 383$ thesis, Université de Provence Aix-Marseille I, Marseille, France, 2016.

[40] A. Bouhuys. Sound-power production in wind instruments. J. Acoust. Soc. Am., 37(3):453-456, 1965. 